\title{
Power Sharing Method Based on Droop Control for Three-Phase UPS Systems
}

\author{
Eng. Mohamed M. Ramadan* Prof. Dr. Magdy A. Koutb \\ Dept. of Industrial Electronics and Control Eng., Faculty of Electronic Eng., Menoufia University, Egypt
}

\begin{abstract}
The main objective of this paper is to improve the power sharing capability and to achieve synchronization between three-phase Uninterruptible power supply (UPS) units in the presence of load interruption. This paper presents a droop-controlled scheme in such a way that the computation of the instantaneous value of the active power and the reactive power are taken as feedback signals to the frequency and voltage restoration control system. The restored frequency and voltage are introduced to voltage controller circuit, which produces a suitable control signal to sinusoidal pulse width modulation circuit (SPWM). Thus producing a suitable trigger pulses to the inverter gate in order to guarantee synchronization between three-phase UPS units. Simulation of two UPS units with the same ratings $(4 \mathrm{KW})$ are carried out using MATLAB. The results show the effectiveness of the proposed control system in achieving synchronization and improving the power sharing capability in the presence of load interruption.

Keywords: Uninterruptible power supply; power sharing; parallel operation; droop control.
\end{abstract}

DOI: $10.7176 / \mathrm{JETP} / 9-4-02$

Publication date: April $30^{\text {th }} 2019$

\section{Introduction}

Uninterruptible power supplies are used to make electrical power system more reliable and continuous. Recently, UPSs usage is widespread in the applications that require power quality and continuous electrical feeding such as computers used for controlling important processes, some medical equipment and data-processing system. UPSs have two modes of operation; stand-alone mode and modular UPS mode, [1]. In stand-alone mode, where full backup of other units are devoted, very high costs are involved with high power UPS. Therefore, using several smaller rated UPS units (modular UPS) in parallel instead of one big unit is more proper, [2].

For several years, great efforts have been devoted to the study of power sharing control strategies for modular UPS. Previous studies indicate that the control strategies require communication lines between the modules such as concentrated method, master slave method and distributed logic control method. This results in increasing the cost of the system, making it difficult to expand the system and the long distance communication lines will be easier to get interfered, thereby reducing system reliability and expandability, [3], [4], [5].

In recent years, research on control strategies without communication links has become very popular. These strategies based on droop concept which improve reliability requirements in addition to avoiding the complexity and high costs. Such a system is easier to expand because of the plug-and-play feature of the modules, [4], [6], [7].

The output of the UPS inverter is required to be sinusoidal signal with minimum distortion. Thus, a combination of pulse width modulation (PWM) circuit and a low pass filter are introduced at the output of the inverter. The PWM has a well performance with linear loads but it doesn't guarantee low distortion of the load voltage with non-linear loads. One way of achieving a clean sinusoidal load voltage is by using a sinusoidal pulse width modulation (SPWM), [8].

This paper presents a droop-controlled scheme based on measuring the instantaneous values of the active power and the reactive power on the tie line and then taken these values as feedback signals to the frequency and voltage restoration control system. The frequency and voltage control signals are introduced to voltage regulator circuit which produces a suitable control signal to SPWM. Thus producing a suitable trigger pulses to the inverter gate in order to guarantee synchronization between three-phase UPS units.

In order to validate the performance of the system in the presence of load interruption, simulation of two parallel-connected 3-phase UPS units with the same ratings is carried out using MATLAB/SIMULINK.

This paper is organized as follows: Section 2 presents the mathematical modeling of the active powerfrequency $(\mathrm{P}-\omega)$ droop and the reactive power-voltage $(\mathrm{Q}-\mathrm{V})$ droop characteristics. Section 3 discusses the restoration process. Simulation results are presented in section 4. Concluding remarks are introduced in Section 5 followed by the list of references.

\section{Mathematical model}

\subsection{System description}

$\mathrm{P}-\omega$ droop and Q-V droop controllers have been successfully adopted in the UPS systems, [10]. Figure 1 shows the connection diagram of distributed inverters of UPS units connected in parallel and sharing power through a tie line.

The equations that describe the active power and the reactive power drawn from each inverter unit to the load 
can be expressed as, [9], [11]

$$
\begin{gathered}
P=\frac{3}{2} \frac{V E}{X} \sin \theta \\
Q=\frac{3}{2} \frac{V E \cos \theta-V^{2}}{X}
\end{gathered}
$$

where, $\mathrm{X}$ is the output reactance of an inverter $X=\omega L=2 \pi f L ; \omega$ angular frequency, $\mathrm{L}$ inductance, $\theta$ is the phase angle between the output voltage of the inverter and the voltage of the tie line, $E$ and $V$ are the amplitude of the output voltage of the inverter and the grid voltage, respectively.

Low pass filters is introduced at the output terminals of each inverter to smooth out the waveform and makes it as close as possible to the required sine wave, [14].

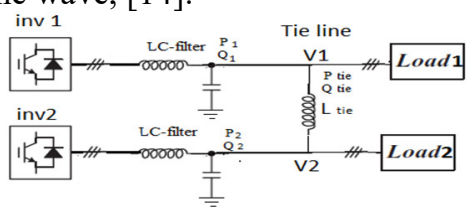

Figure 1. Simplified circuit of the system.

\section{$2.2 P-\omega$ droop and $Q-V$ droop characteristic}

As can be seen from Figure 2, the basic idea of this control level is to mimic the behavior of a synchronous generator, which is to reduce the frequency as the active power increases, [6], [11]. The reactive power drawn from the inverter increases, the voltage decreases, [12], [13].

$$
\begin{aligned}
\omega_{\mathrm{i}} & =\omega_{2, \mathrm{i}}-\mathrm{m}_{\mathrm{P}}\left(\mathrm{p}_{2}-\mathrm{p}_{\mathrm{i}}\right) \\
\mathrm{V}_{\mathrm{i}} & =\mathrm{V}_{2, \mathrm{i}}-\mathrm{n}_{\mathrm{Q}}\left(\mathrm{Q}_{2}-\mathrm{Q}_{\mathrm{i}}\right)
\end{aligned}
$$

where, $\mathrm{m}_{\mathrm{P}}$ is the slope of the $\mathrm{P}-\omega$ characteristics, $\mathrm{n}_{\mathrm{Q}}$ is the slope of the $\mathrm{Q}-\mathrm{V}$ characteristics ; $\mathrm{i}$ the index representing each UPS, $\omega_{i}$ is the rated angular frequency of the UPS unit at the rated output active power $P_{i} . \omega_{2, i}$ is the angular frequency when the inverter works at the output active power of $\mathrm{P}_{2} . \mathrm{V}_{\mathrm{i}}$ is the rated voltage of the UPS unit at the rated output reactive power $\mathrm{Q}_{\mathrm{i}} . \mathrm{V}_{2, \mathrm{i}}$ is the voltage when the inverter works at the output reactive power of $\mathrm{Q}_{2}$.

To achieve power sharing, synchronization between uninterruptible power supply must be achieved. If we have two UPS units working in parallel at the same rated frequency and voltage, then:

$$
\begin{aligned}
& \mathrm{m}_{\mathrm{P} 1} \mathrm{P}_{0,1}=\mathrm{m}_{\mathrm{P} 2} \mathrm{P}_{0,2} \\
& \mathrm{n}_{\mathrm{Q} 1} \mathrm{Q}_{0,1}=\mathrm{n}_{\mathrm{Q} 2} \mathrm{Q}_{0,2}
\end{aligned}
$$

\section{Control design}

In the droop-controlled scheme the active power $(\mathrm{P})$ and the reactive power $(\mathrm{Q})$ are measured, then the instantaneous values of $\mathrm{P}$ and $\mathrm{Q}$ are taken as feedback signals to the frequency and voltage restoration control system. The restored frequency and voltage are introduced to gate pulse generator circuit in which the voltage regulator produces a suitable control signal to sinusoidal pulse width modulation (SPWM). Thus, producing a suitable trigger pulses to the inverter gates which guarantee synchronization between three-phase UPS units. Figure 3 shows the droop-controlled scheme of one UPS unit.

A restoration mechanism is also proposed to bring frequency $\omega$ and voltage $\mathrm{V}$ to its rated value in order to satisfy synchronization between UPS units, [10].

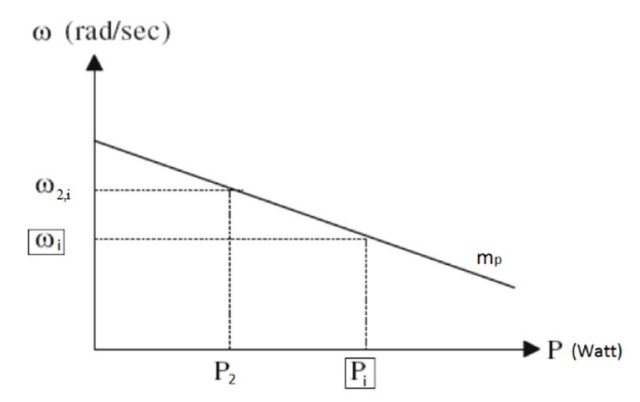

(a) Active power - frequency droop characteristics

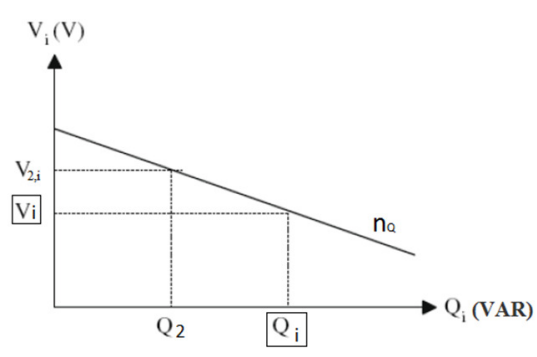

(b) Reactive power - voltage droop characteristics. 
Figure 2. Droop characteristics.

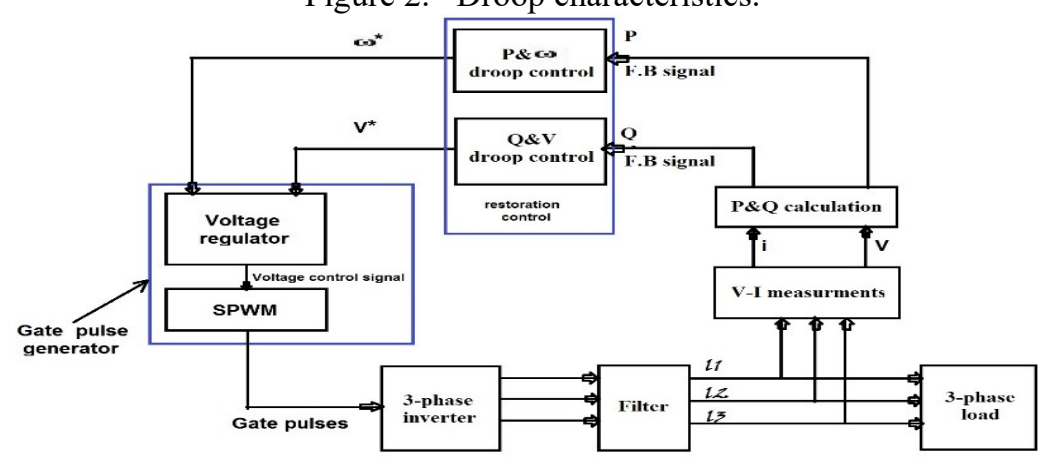

Figure 3. The droop-controlled scheme of one UPS unit.

\subsection{Frequency droop restoration control}

Initially, the UPS unit operates with nominal frequency $\left(\omega_{0}\right)$ at the active power level of $\left(\mathrm{P}_{0}\right)$ on the line $\mathrm{L}_{1}$. If the load power reduces to $P_{1}$, the frequency of the unit shifts to a new value $\left(\omega_{0}\right)$. In order to restore the frequency back to the nominal value, the droop line should be shifted down as shown in Figure 4 . The new line $\mathrm{L}_{2}$ has the same slope as the original one. The output of each inverter must have the same frequency (rated one) after controlled and from equation (3).

$$
\omega_{0}=\mathrm{m}_{\mathrm{p} 1} \mathrm{P}_{1}=\mathrm{m}_{\mathrm{p} 2} \mathrm{P}_{2}
$$

The active power shared between inverters are changed due to the change of the load active power $\Delta \mathrm{P}_{\mathrm{L}}$.

$$
\Delta \omega_{\mathrm{i}}=\mathrm{m}_{\mathrm{pi}} \Delta \mathrm{P}_{\mathrm{i}}
$$

where, $\Delta \mathrm{P}_{\mathrm{i}}$ is the change in active power and $\Delta \omega_{\mathrm{i}}$ is the change in the frequency of the $\mathrm{i}^{\text {th }}$ inverter unit. In equation (3), $\mathrm{P}_{2, \mathrm{i}}$ is changed for each unit to restore the frequency during load sharing.

$$
\begin{gathered}
\Delta \mathrm{P}_{2, \mathrm{i}}=\left(\mathrm{K}_{\mathrm{res}} * \mathrm{P}_{\mathrm{Ri}}\right) * \Delta \omega_{\mathrm{i}} \\
\mathrm{P}_{2, \mathrm{i}}=\left(\mathrm{K}_{\mathrm{res}} * \mathrm{P}_{\mathrm{Ri}}\right) * \int \Delta \omega_{\mathrm{i}}
\end{gathered}
$$

The " $\mathrm{K}_{\mathrm{res}} \mathrm{P}_{\mathrm{Ri}}$ " coefficients in these equations determine the frequency restoration ratio. Equations (3), (8) and (10) determine the block diagram shown in Figure 5 of the frequency restoration control.

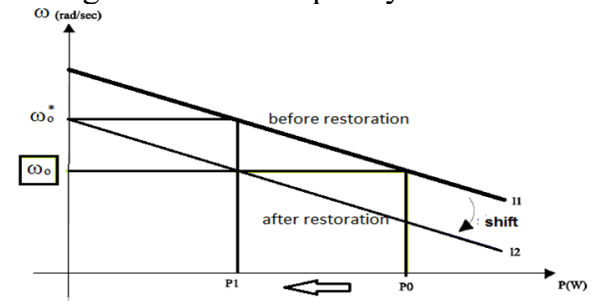

Figure 4. Frequency restoration by shifting the active power-freq. droop characteristics.

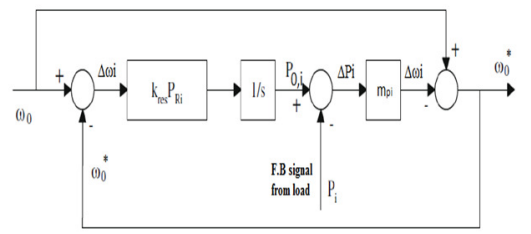

Figure 5. Frequency restoration block diagram.

\subsection{Voltage droop restoration control}

Similar to frequency restoration algorithm, voltage restoration is required upon the change of the reactive power of the load. In equation (4), $\mathrm{Q}_{2, \mathrm{i}}$ is changed for each unit to restore the voltage during load sharing.

$$
\begin{aligned}
& \Delta \mathrm{Q}_{2, \mathrm{i}}=\left(\mathrm{Y}_{\text {res }} * \mathrm{Q}_{\mathrm{Ri}}\right)^{*} \Delta \mathrm{V}_{\mathrm{i}} \\
& \mathrm{Q}_{2, \mathrm{i}}=\left(\mathrm{Y}_{\text {res }}{ }^{*} \mathrm{Q}_{\mathrm{Ri}}\right)^{*} \Delta \Delta \mathrm{V}_{\mathrm{i}}
\end{aligned}
$$

The " $Y_{\text {res }} Q_{R i}$ " coefficients in these equations determine the Voltage restoration ratio (gain). Equations (4) and (12) determine the block diagram shown in Figure 6 of the voltage restoration control.

\section{Simulation results}

In order to validate the performance of the proposed system in the presence of load interruption, MATLAB/SIMULINK is used for the simulation of two parallel-connected 3-phase UPS units with the same ratings $(4 \mathrm{KW})$. The simulation is made for 2 Seconds. Initially, the loads $\mathrm{z}_{1}$ and $\mathrm{z}_{2}$ are connected on the tie line and the UPS units worked in the normal case. When the time reaches $0.5 \mathrm{Sec}$, an interruption is introduced by adding 
additional load $z_{\text {tr }}$ connected on the tie line in parallel with the loads $z_{1}, z_{2}$. When the time reaches 1 Sec the load $z_{t r}$ is disconnected from the tie line and the units returned to work in the normal case. Table 1 shows the parameters used in the simulation.

Figure 7 shows the output voltage and current of the UPS 1 and $\mathrm{UPS}_{2}$. The voltage is maintained at its rated value 380 Volt as shown in Figure 7-a and Figure 7-c. When the load $z_{\text {tr }}$ is connected on the tie line in parallel with the loads $\mathrm{Z}_{1}, \mathrm{Z}_{2}$ at $\mathrm{T}=0.5 \mathrm{Sec}$ the total impedance decreased so the current is increased. At $\mathrm{T}=1 \mathrm{Sec}$ the load $\mathrm{z}_{\mathrm{tr}}$ is disconnected so the current is returned back to the first value as shown in Figure 7-b and Figure 7-d.

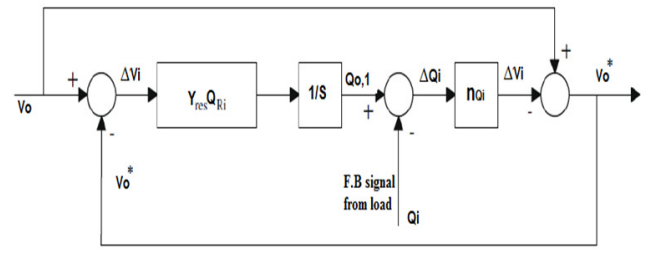

Figure 6. Voltage restoration block diagram.

Table 1. Simulation parameters.

\begin{tabular}{|l|l|l|l|}
\hline Rated Frequency $\left(f_{0}\right)$ & $50 \mathrm{~Hz}$ & Rated Voltage $\left(V_{0}\right)$ & 380 Volt \\
\hline Freq. restoration gain & 900 & voltage restoration gain & 600 \\
\hline $\mathrm{m}_{\mathrm{P}}$ & -0.04 & $\mathrm{n}_{\mathrm{Q}}$ & -0.02 \\
\hline PWM_switching freq. & $1000 \mathrm{~Hz}$ & $z_{1,2}=140 \Omega+13 \mathrm{mH}$ & $z_{\text {tr }}=80 \Omega+1 \mathrm{mh}$ \\
\hline Filter & $R=1 \Omega$ & $L=5 \mathrm{mH}$ & $C=1200 \mu \mathrm{F}$ \\
\hline
\end{tabular}

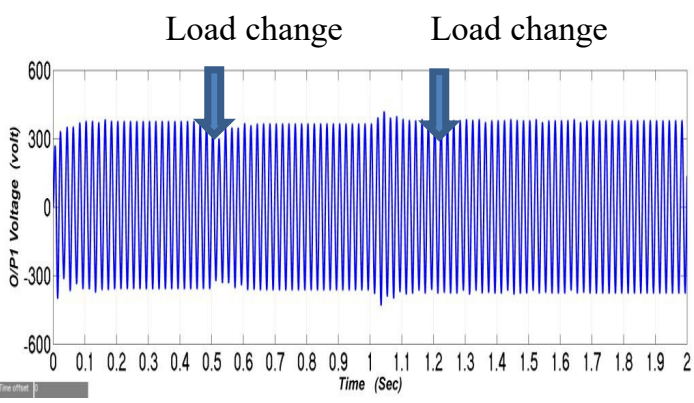

(a) $\mathrm{UPS}_{1,2}$ output phase voltage waveform

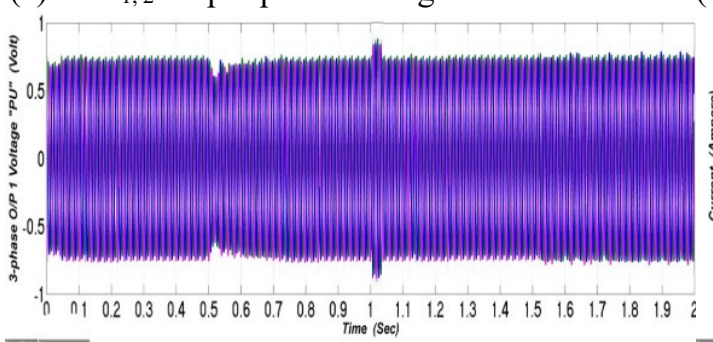

(c) UPS 1,2 output voltage waveform "3-phase".

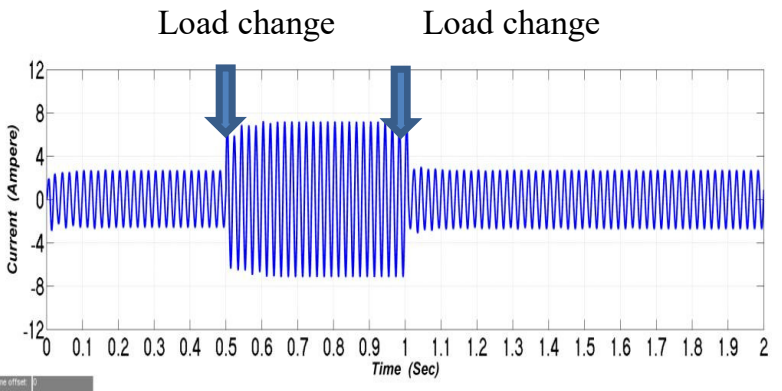

(b) $\mathrm{UPS}_{1,2}$ output phase current waveform.

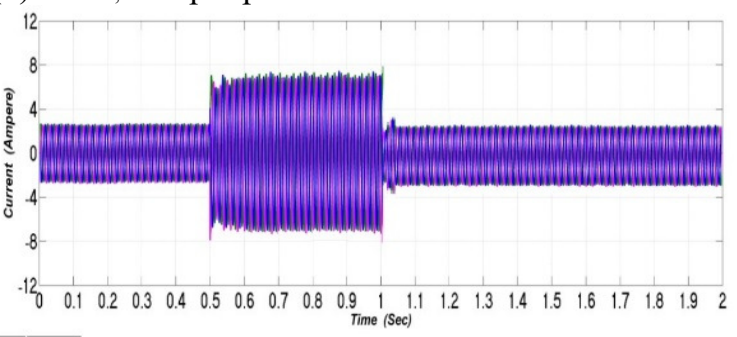

(d) UPS 1,2 output current waveform "3-phase".

Figure 7. Variation of the output voltage and current of the UPS system.

Figure 8 shows the effect of load interruption on the active power and frequency. The change in the active power of $\mathrm{UPS}_{1}$ and $\mathrm{UPS}_{2}$ occurred at $\mathrm{T}=0.5 \mathrm{Sec}$ and $\mathrm{T}=1 \mathrm{Sec}$ as shown in Fig. 8-a. The frequency is instantaneously interrupted then returned back to its initial value $50 \mathrm{~Hz}$ as shown in Fig. 8-b. This behavior is due to the frequency restoration control.

Fig. 9 shows the effect of load interruption on the reactive power and voltage. The change in the reactive power of $\mathrm{UPS}_{1}$ and $\mathrm{UPS}_{2}$ occurred at $\mathrm{T}=0.5 \mathrm{Sec}$ and $\mathrm{T}=1 \mathrm{Sec}$ as shown in Fig. 9-a. The voltage is instantaneously interrupted then returned back to its initial value 380 Volt as shown in Fig. 9-b. This behavior is due to the voltage restoration control. Thus, the restoration droop circuits regulate the system frequency and voltage (which satisfy synchronization) in the presence of load interruption and the UPS units are sharing load correctly. 


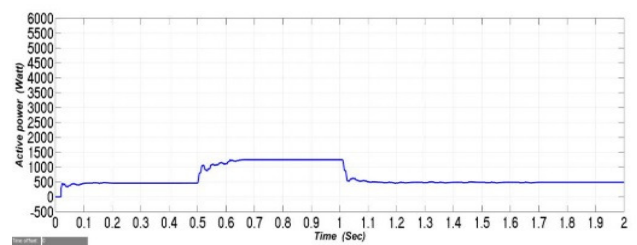

(a) $\mathrm{UPS}_{1,2}$ active power waveform.

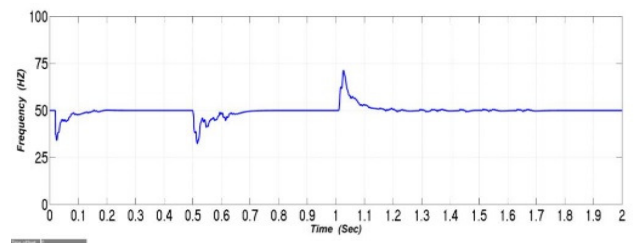

(b) $\mathrm{UPS}_{1,2}$ frequency adjustment.

Figure 8. Effect of load interruption on the active power and frequency.

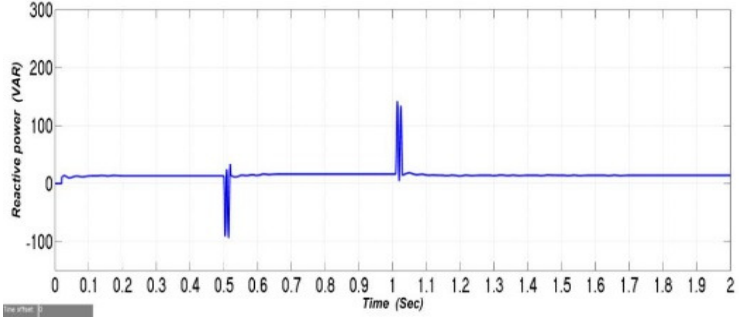

(a) $\mathrm{UPS}_{1,2}$ reactive power waveform.

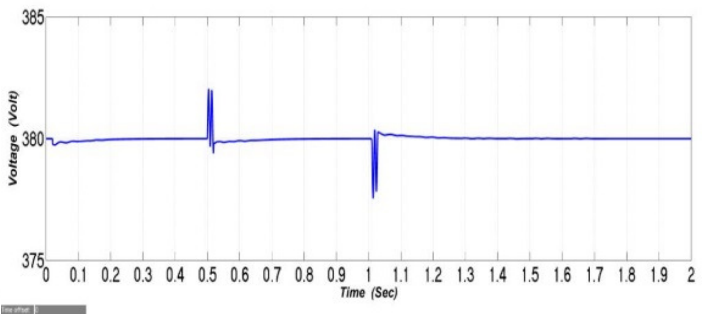

(b) $\mathrm{UPS}_{1,2}$ voltage adjustment.

Figure 9. Effect of load interruption on the reactive power and voltage.

Since the UPS 1 and UPS 2 units have the same ratings, they share the total load equally. Thus, the two UPS units have the same voltage, current, active power, reactive power and frequency waveforms as shown in Fig.7, Fig. 8 and Fig. 9.

Figure 10 shows the root mean square error (RMSE) of the output voltage magnitude variation of $\mathrm{UPS}_{1}$ and $\mathrm{UPS}_{2}$ units when load change occurred at $0.5 \mathrm{Sec}$ and $1 \mathrm{Sec}$. The desired value of voltage magnitude $=380$ Volt. The RMSE of the output voltage variation of UPS unit reaches zero within a short period. This means that the system response goes to the desired value. Thus, the droop-controlled method succeeded in improving the power sharing capability in the presence of load interruption.

\section{Conclusion}

The effectiveness of the droop-controlled scheme in improving synchronization and power sharing capability in the presence of load interruption is presented. In this control system the instantaneous values of the active power and the reactive power are taken as feedback signals to the frequency and voltage restoration control system. The restored frequency and voltage are introduced to gate pulse generator circuit, which produces a suitable control signal to the inverter gate. Simulations of two parallel-connected 3-phase UPS units with the same ratings (4 KW) are carried out using MATLAB and the results show that the restoration droop circuits regulate the system frequency and voltage efficiently in the presence of load interruption. The RMSE of the output voltage magnitude of UPSs unit reaches zero within a short period. Since the UPS1 and UPS2 units have the same ratings, they share the total load equally.

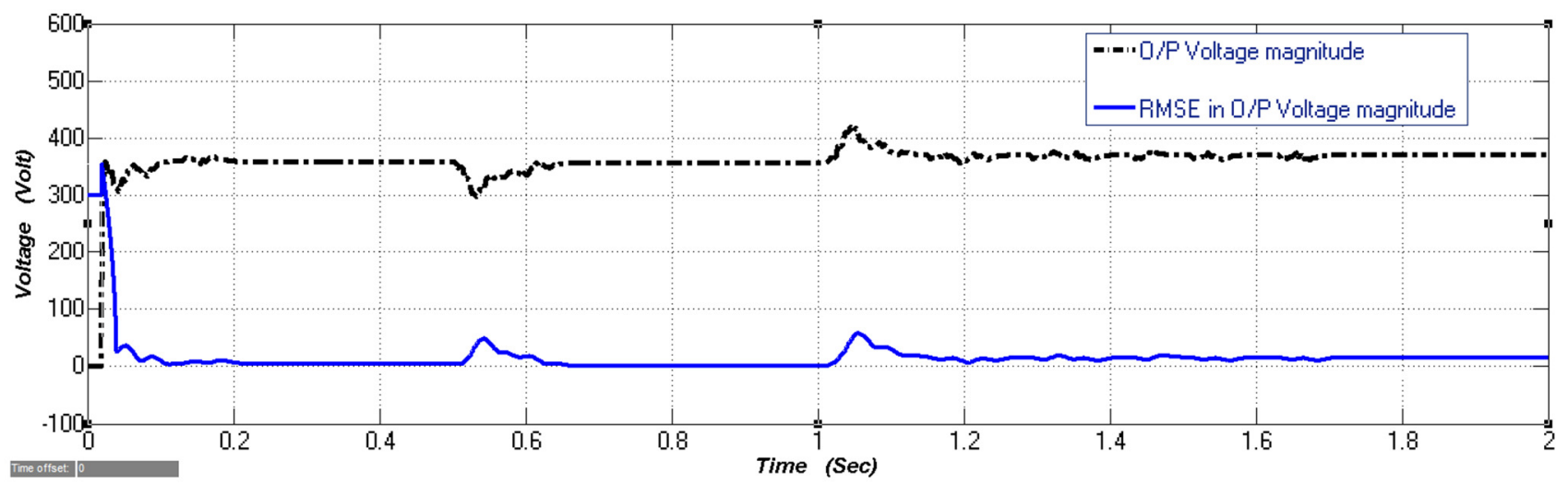

Figure 10 RMSE of output voltage magnitude variation of $\mathrm{UPS}_{1,2}$ units.

\section{References}

[1] John W. Simpson, Florian D“orfler and Francesco Bullo, " Voltage Stabilization in Microgrids via Quadratic Droop Control ", in Decision and Control (CDC), 2013 IEEE 52nd Annual Conference, Florence, Italy, Dec. 2013, pp. $7582-7589$.

[2] Ashdown B, Poulin J., "Distributed power-a solution for the 90s", in International telecommunications energy 
conference (INTELEC), Paris, France, 1993, pp 47-51.

[3] K.-D. Wu, J.-C. Wu, H.-L. Jou, C.-Y. Chen and C.-Y. Lin, " Simplified control method for parallel-connected DC/AC inverters", IEE Proc.-Electr. Power Appl., vol. 153, no. 6, pp. 787-792, November 2006.

[4] Duan Shanxu, Meng Yu, Xiong Jian, Kang Yong, Chen Jian, " Parallel Operation Control Technique of Voltage Source Inverters in UPS ", in IEEE 1999 International Conference on Power Electronics and Drive Systems, Hong Kong, Hong Kong, July 1999, pp883-887.

[5] Mukul C.Chandorkar, Deepakraj M.Divan and Rambabu Adapa, " Control of Parallel Connected Inverters in Standalone ac Supply Systems ", JEEE Trans. Ind. Applicat.,vo1.29, no.1, pp.136-143, Feb. 1993.

[6] Hua Han, Xiaochao Hou, Jian Yang," Review of Power Sharing Control Strategies for Islanding Operation of AC Microgrids ", IEEE Transaction on Smart Grid, vol.7, no. 1, pp. 200-215, June 2015.

[7] R. Majumder, G. Ledwich and A. Ghosh, " Droop control of converter interfaced microsources in rural distributed generation ", IEEE Trans. Power Del., vol. 25, no. 4, pp. 2768-2778, Oct. 2010.

[8] Naser M.Abdel-Rahim, John E.Quaicoe, "Analysis and Design of a Multiple Feedback Loop Control Strategy for Single-phase Voltage Source UPS Inverters", IEEE Transactions on Power Electronics, vol. 11, no. 4, pp. 532-541, Oct. 1996.

[9] Josep M,Juan c,Jose Matas,M Castilla,Luis G, " Control strategy for flexiblemicrogrid based parallel line interactive UPS system ", IEEE Transaction on Industerial Electronics, vol. 56, no. 3, pp. 726-736, Mach 2009.

[10] Chia-Tse Lee, Chia-Chi and Po-T Cheng, " A New Droop Control Method for the Autonomous Operation of Distributed Energy Resource Interface Converters ", IEEE transactions on power electronics, vol. 28, no. 4, pp. 1980-1992, 2013.

[11] Josep M. Guerrero, Néstor Berbel, Luis García de Vicuña, José Matas, Jaume Miret and Miguel Castilla, " Droop Control Method for the Parallel Operation of Online Uninterruptible Power Systems Using Resistive Output Impedance ", in 21st IEEE Anual Applied Power Electronics Conference and Exposition, Dallas, TX, USA, March 2006, pp. 1716-1722.

[12] Lin-Yu Lu, " Consensus-Based P-f and Q-V Droop control for multiple parallel-connected inverters in lossy network ", in Industrial Electronics (ISIE), 2013 IEEE International Symposium on, Taipei, Taiwan, May 2013, pp. 1-6.

[13] Chia-Chi Chu and Lin-Yu Lu, " Robust Consensus-Based Droop Control for Multiple Power Converters in Isolated Micro-Grids ", in Circuits and Systems (ISCAS), 2014 IEEE International Symposium on, Melbourne VIC, Australia, June 2014, pp. 1820-823.

[14] H. Akagi, Y. Kanazawa and A. Nabae," Generalized theory of the instantaneous reactive power in three-phase circuits ", IEEE Transactions on Instrumentation and Measurement, vol. 54, no. 1, pp. 293-297, Feb. 1996.

Mohamed M. Ramadan received the B. Sc. degrees in industrial electronics and control Engineering from Faculty of Electronic Engineering, Menoufia University, Egypt in 2013.

Work as an Electrical Engineer at Ministry of housing - New Urban Communities authority - Sadat city authority since 2015. His research interests include UPS microgrids, power control of hybrid solar/wind systems and modern control algorithms.

Magdy A. Koutb received his B.Sc. and M.Sc. degrees in Industrial Electronics and Control Engineering from the Menoufia University, Egypt, in 1977 and 1981, respectively, and the Ph.D. degree in control systems from Poland, in 1985. He was a vice dean of the faculty of electronic engineering for postgraduate studies and research from 2003 to 2009. Currently, he is a professor emeritus in the Department of industrial electronics and control Engineering at Menoufia University, Egypt.

He has published about 100 refereed journal and conference papers. His research interest covers robotics, feedback control systems, electrical power systems and control theory. 